\title{
Development of Scaled Real Time Augmented Reality Sandbox
}

\author{
Fahad Muhyialdeen Aljabal, Hezerul Abdul Karim, Mazlan Mahadzir, \\ Mohd Hafizuddin Mohd Yusof, Che Zulkhairi Abdullah
}

\begin{abstract}
This paper presents a scaled version of Augmented Reality Sandbox (ARSAND). Original ARSAND consist of short throw projector, Kinect $3 D$ camera, dedicated computer with high end graphic card and sandbox. ARSAND has been gaining recognition and popularity for its rapid and accurate capabilities in designing landscapes and simulating geographical real-world terrain. The proposed scaled version of the ARSAND consists of ultra-short throw projector with different configuration, Kinect 3 D camera, dedicated computer with high end graphic card, and calibrated sandbox with less amount of sand. The proposed scaled version of ARSAND is able to perform basic functions of the original ARSAND such as simulating real-world terrain and rain fall.
\end{abstract}

Index Terms: Augmented Reality Sandbox, educational tool, geographical terrain.

\section{INTRODUCTION}

Given the fact that ARSAND tool is now actively implemented and used in many fields, it is worth mentioning that such a tool was firstly inspired and developed by the researchers at UC Davis to overcome the limitations and to simplify the learning process for geoscience students [1].

This tool has achieved its objective by making use of Augmented Reality (AR) technology which formed the base layer and made this invention possible. AR has been defined as "blending (augmenting) virtual data information, rich media and even live action with what is seen in the real world, for the purpose of enhancing the information we can perceive with our senses" [1] as illustrated in Fig. 1.

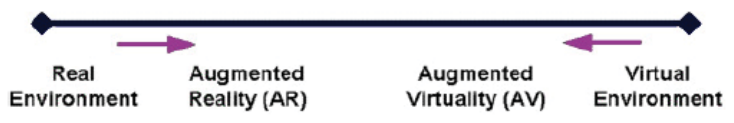

Fig. 1: Milgram's Reality-Virtually continuum

Revised Manuscript Received on August 18, 2019

Fahad Muhyialdeen Aljabal, Faculty of Engineering, Multimedia University, Cyberjaya, Malaysia.

Hezerul Abdul Karim, Faculty of Engineering, Multimedia University, Cyberjaya, Malaysia

Mazlan Mahadzir, Faculty of Creative Multimedia, Multimedia University, Cyberjaya, Malaysia.

Mohd Hafizuddin Mohd Yusof, Faculty of Creative Multimedia, Multimedia University, Cyberjaya, Malaysia.

Che Zulkhairi Abdullah, University of Salford, Manchester, United Kingdom.
The 2D traditional impractical method that was used as the main tool of education had to be replaced and improved as it lacks the active learning interaction that students need to digest and imagine the concepts upon them [2]. Montessori method has shown that students are most efficiently learning when they are experimenting and physically interacting with an educational object [3]. This study can simply explain why and how children can learn and develop their skills by solely interacting with tangible objects such as toys, building blocks, puzzles.

The ARSAND mainly consists of short throw projector, Kinect 3D camera, dedicated computer with high end graphic card, and sandbox [4]. ARSAND technically operates in real- time when the Kinect 3D camera senses the changes in height and depth that are being made on the sand by the user. The Kinect will then make an image of the topography map of the box. This map data will be sent to the computer equipped with AR sandbox software that will analyse it and sketch a colour-elevated map ranging from cold blue representing sea level or bottom of the box to dark red representing tip of the mountains/heights. This sketch will then be sent to the projector that will project it on the sandbox with precise contour lines according to the elevation of the heights formed earlier with the sand [5].

\section{RELATED WORKS}

\section{A. UC Davis Augmented Reality Sandbox}

Fig. 2 shows the schematic diagram of the ARSAND proposed in [1]. The surface of the sand is scanned and recorded with $3 \mathrm{D}$ camera that is mounted on the wooden edge on top of the box. The camera main function is to record the movement, shape, and height of the sand that is being moulded by the user and transfer it to a computer. This recoded data will be processed by the computer and coloured elevated map will be sketched by the AR sandbox software.

After processing, an output of a real time video will be generated and projected on the sand using a projector that is mounted on top of the box. The 3D camera will generate an IR pulse within the range of its field of view and that is the reason for mounting the camera at a standard height of one meter above the middle of the box. 
The generated IR pulses will hit the surface of the sand and gets reflected. These reflected pulses will help the sensor in recording the altitude and shape of the sand. These records will help in producing a detailed topographic map showing the exact height of the sand at each

point in the box.

The video information that is produced by the computer is extracted with the use of software that has been developed by the same inventor. The software produces a topographic map with coloured contour lines changing from cold blue to warm red. This information is then projected onto the surface which will allow the users to see complete $3 \mathrm{D}$ image of the desired topographical map [2].

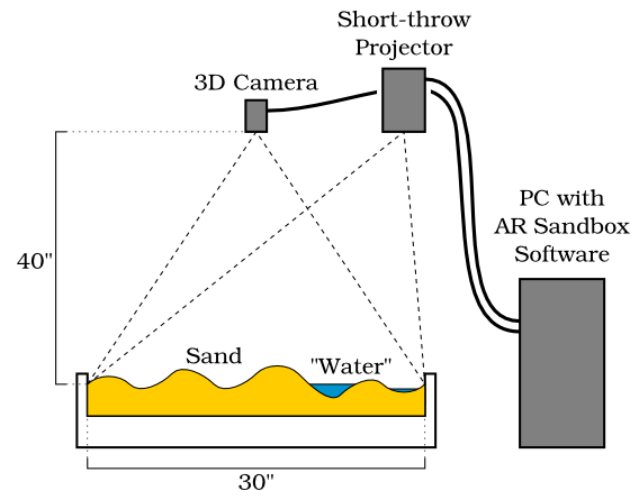

Fig. 2: The schematics of AR sandbox

\section{B. Tangible Modelling AR Sandbox}

Tangible landscape is a new technology that allows users to rapidly and intuitively be able to design different kind of landscapes that have been simulated and modelled geospatially. It is a tangible interface where users are having the advantage of interacting naturally with 3D physical models and shape them accordingly. Tangible landscapes are mostly created by coupling a physical and digital model of a landscape through a real-time cycle of physical manipulation [3].

Besides earthwork, topographic modelling is considered one of the main tasks that a landscape architecture should be able to design. These models mostly come in a form of data that derived from field surveys.

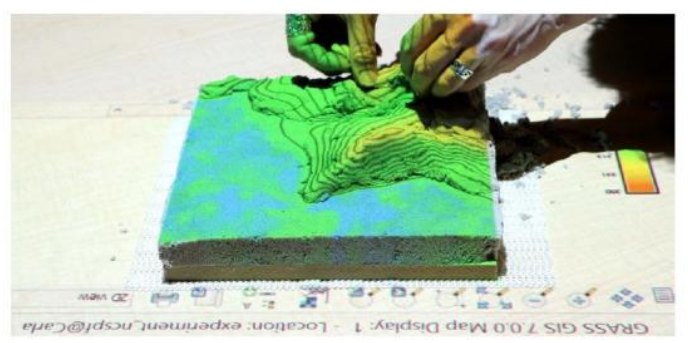

Fig. 3: A participant sculpts the study landscape using the projected elevation and contour

The tangible modelling architects used to design such a topography using analogue methods where contours maps are sculptured by hand as shown in Fig. 3. Considering it as more of intuitive way of designing but less precise than the digital method which uses Rhinoceros software to simulate the topographical map. Digital method provides more accuracy and dynamic modes of visualization.

\section{Virtual Reality Sandbox System}

AR sandbox has shown a limitation when it comes to simulating real-time water cycle due to the fact that the current system of AR sandboxes does not include non-interactive 2D kind of projection, besides the shadowing issue that could limit the accuracy of water cycle simulation [9]. Thus, an extended system was needed and that is where virtual reality sandbox or VR sandbox comes to play. The proposed system extended the current system with a virtual reality. It was built with triple Kinects, sensor for sand depth, tracking the physical hand with the use of leap motion, and finally the main component VR as shown in Fig. 4. The new proposed system was setup to navigate through the space of haptic redirection.

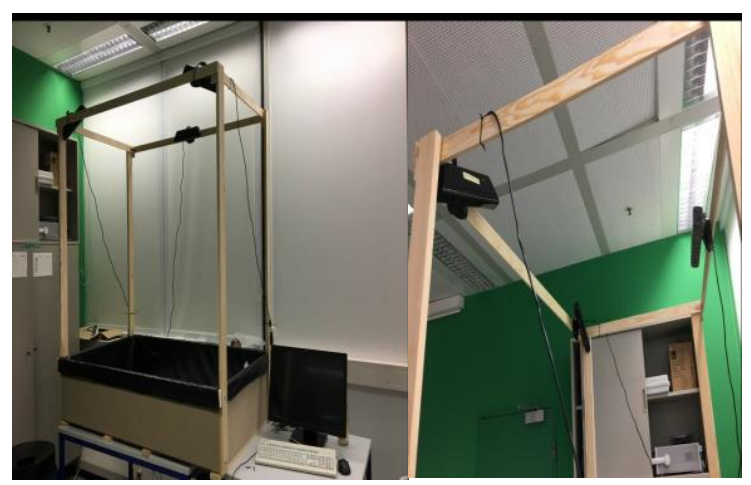

Fig. 4: Virtual Reality Sandbox

The sandbox in Fig. 4 was slightly bigger than the AR sandbox setup. It had the dimension of $140 \mathrm{~cm} \times 80 \mathrm{~cm} \mathrm{x}$ $30 \mathrm{~cm}$. This change in size was mainly required to give more freedom for the users and to guarantee future modification. For tracking, a Kinect of version 1 was used just like the old setup but it was mounted at $120 \mathrm{~cm}$ above the box which makes slightly higher in order to adapt with the bigger size of the sand and match its field of view. The movement of sand was sensed from three different angle by the three Kinect that were mounted to form a tringle. Other sensors like leap motion were mounted beside the Head Mounted Display (HMD) and they were used to sense user's hand movement The software used was similar to the one used in the old setup with slight modification for instance it was running on Windows 10 instead of Linux Mint.

\section{PROPOSED SYSTEM}

The proposed system as shown in Fig. 5 used similar setup as the original system in Fig. 2. The main differences are the used of ultra-short throw projector, amount and type of sand used and the calibration parameters.

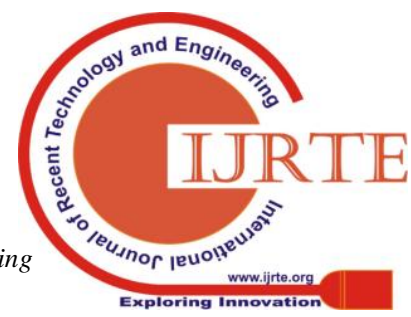


AR sandbox technically works as shown in Fig. 6. In the beginning, the Kinect 3D camera senses the changes in height and depth that are being made on the sand. The Kinect will then make an image of the topography map of the box. This map data will be sent to the computer ARSAND software that will analyses it and sketch a colour-elevated map ranging from blue representing sea level or bottom of the box to dark red representing tip of the mountains/heights. This sketch will then be sent to the projector that will project it on the sandbox with precise contour lines according to the elevation of the heights formed earlier.

\section{A. Ultra-Short Throw Projector}

In general, there are three kind of projectors and their throw distances that makes up the difference between their functionality and purpose. Table I shows the projectors and their corresponding throw distances.
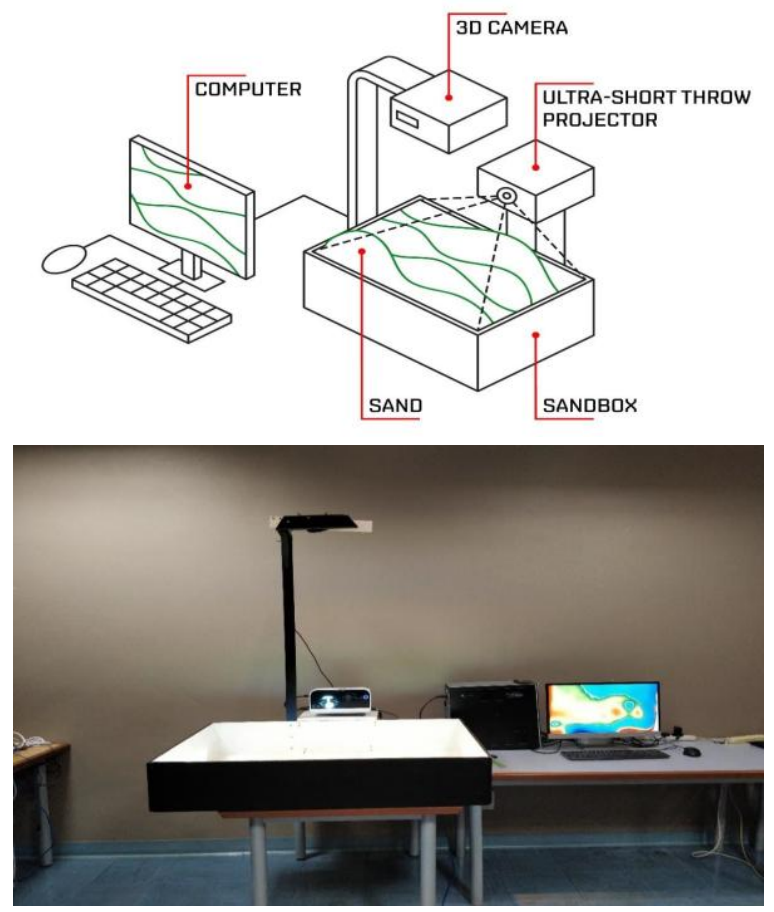

Fig. 5: The proposed physical setup

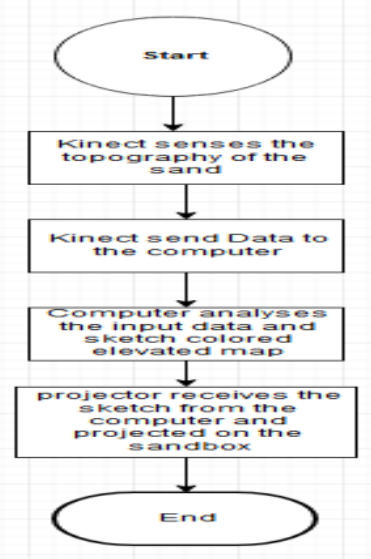

TABLE I. PROJECTORS TYPES AND CHARACTERISTICS

\begin{tabular}{|l|l|}
\hline Projector & Throw distance \\
\hline Standard or long throw & $(244-305 \mathrm{~cm})$ \\
\hline Short throw & $(90-120 \mathrm{~cm})$ \\
\hline Ultra-short throw & $(8-50 \mathrm{~cm})$ \\
\hline
\end{tabular}

Ideally, the projector recommended by the UC Davis setup is a short throw projector, as it is mounted within the distance of 1 meter above the surface of the sand and its ability to project vertically makes it a perfect candidate for this kind of projects. However, in this project, an ultra-short throw projector was used given its availability and to compromise the cost of the project.

In this project the problem faced with the ultra-short throw projectors is their non-vertical projection throw and the very short throw distance. The two mentioned above difficulties were eliminated by mounting the ultra-short throw projector on a side table and within 10-20 cm apart from the sand surface which gives it the required space needed for precise projection that could fit the box. The projector in Fig. 5 shows an ultra-short projector while it is projecting on the side.

\section{B. Sand}

There are two main factors that should concern the developers when planning on what sand should be used for the project. Firstly, the sand should be of specific characteristics it has to reflect the $3 \mathrm{D}$ image projected on it thus it must be white, reflective and fine kind of sand. The recommended sand by UC Davis team is a play 'Sandtastik' sand. Given its availability and low price in the USA makes a perfect fit for their project. In Malaysia where this project is being developed the recommended sand was hardly available and if available, they are very expensive due to the shipment fees. All these factors have triggered the need for a replacement sand leading the development team to decide on a different brand of sand but carries the same main required characteristics.

Secondly, is the health concerns considering the time spent while interacting with the sand and moulding it. Developers should worry about health consequences that might be caused from interacting with a dusty sand. The sand must be a silica free, non-toxic and dust free causing no health issues when inhaling and dealing with it in the long term. Table II shows a cost comparison between recommended sand and proposed sand.

\section{TABLE II. COST OF RECOMMENDED AND PROPOSED} SAND

\begin{tabular}{|c|c|c|c|}
\hline \multicolumn{2}{|c|}{ Recommended (Sandtastik) } & \multicolumn{2}{|c|}{ Proposed (Natural sand) } \\
\hline Availability & Cost & $\begin{array}{l}\text { Availabilit } \\
\mathrm{y}\end{array}$ & Cost \\
\hline $\begin{array}{l}\text { Not } \\
\text { available }\end{array}$ & $\begin{array}{l}\text { RM8356 for } \\
98 \mathrm{Kg}\end{array}$ & Available & $\begin{array}{l}\text { RM1586 for } \\
98 \mathrm{Kg}\end{array}$ \\
\hline
\end{tabular}




\section{Development of Scaled Real Time Augmented Reality Sandbox}

\section{Calibration Method}

The measurements that have been extracted from the system calibration such as base plane and the position of the four corners should be saved into a file of type text. When running the ARSAND software for the first time the data in this file should be provided to the software. This data will help in calculating a precise topography.

Table III shows the base of the box plane equation, where (-113) represents the sea level that was introduced to the Kinect sensors in order to comply with the hardware components available. The other three measurements represent the $(\mathrm{x}, \mathrm{y}, \mathrm{z})$ positions of the box base with respect to the Kinect.

TABLE III. BASE PLANE EQUATIONS

\begin{tabular}{|c|l|}
\hline $\mathbf{x}, \mathbf{y}, \mathbf{x}$ position of the box base & Sea Level \\
\hline$(0.0745142,-0.100165,0.992177)$ & -113.874 \\
\hline
\end{tabular}

Fig. 7 shows the positions of the four corners that were introduced to the Kinect. Theses corners were measured within the Ultra-short throw projected region. This change of the corner positions is what led to obtaining more accurate results. The corners have been measured in the following order ( 1 lower left -2 lower right) then (3 upper right -4 upper left).

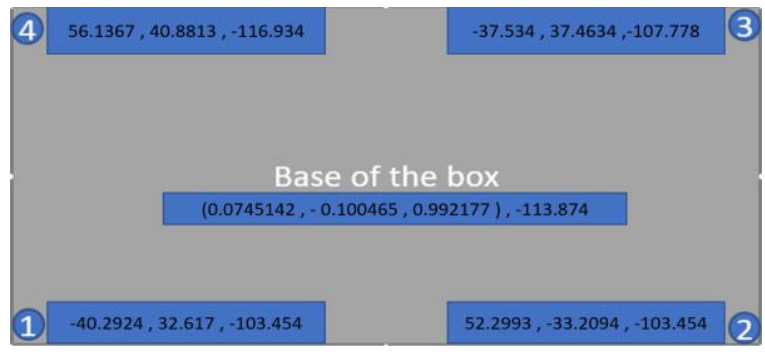

Fig. 7: Measurement of the four corners positions on the (x, $\mathrm{y}, \mathrm{z})$ axis

Modification has been made on the calibration method that is recommended and used by UC Davis development team. For the sake of simplicity, UC Davis method will be called Method (1). This modification has yielded to a more accurate result. This accuracy in results was not due to UC Davis method imperfections or limitations but rather the differences in the hardware components and the proposed physical setup. It was noticeable that the hardware components and the physical setup used in theses project were developed according to UC Davis recommendations. In another word Method (1) or UC Davis method works only when the hardware components and the physical setup are exactly as recommended by them. Due to the unavailability of the hardware components in this project a modification to the whole process was needed leading to a new calibration method or Method (2).
In this method the development team introduced four different corner positions. The positions were defined at the corner of the projection region given the ultra-short throw projector was not fully projecting within the physical interior of the box. Table IV shows the base plane equation obtained using Method (1) and Method (2)

TABLE IV. BASE PLANE EQUATIONS

Method $1(0.0658745,-0.101587,0.9845111),-122.958$

\begin{tabular}{|l|lll|lll|}
\hline $\begin{array}{l}\text { Corner's } \\
\text { position }\end{array}$ & \multicolumn{4}{|l|}{ Method (1) } & & \multicolumn{3}{l|}{ Method (2) } \\
\hline $\begin{array}{l}\text { Lower } \\
\text { left }\end{array}$ & $\mathrm{X}$ & $\mathrm{Y}$ & $\mathrm{Z}$ & $\mathrm{X}$ & $\mathrm{Y}$ & $\mathrm{Z}$ \\
\hline Lower & $\mathrm{X} .35$ & 35.72 & -105.56 & -40.29 & 32.62 & 103.45 \\
right & 50.13 & -30.29 & 101.59 & 52.30 & -33.21 & 103.45 \\
\hline Upper & $\mathrm{X}$ & $\mathrm{Y}$ & $\mathrm{Z}$ & $\mathrm{X}$ & $\mathrm{Y}$ & $\mathrm{Z}$ \\
right & -34.59 & 31.60 & -102.88 & -37.53 & 37.46 & -107.78 \\
\hline $\begin{array}{l}\text { Upper } \\
\text { left }\end{array}$ & $\mathrm{X}$ & $\mathrm{Y}$ & $\mathrm{Z}$ & $\mathrm{X}$ & $\mathrm{Y}$ & $\mathrm{Z}$ \\
& 59.78 & 46.87 & -113.36 & 56.14 & -40.88 & 116.93 \\
\hline
\end{tabular}

Method 2 (0.0745142, $-0.100165,0.992177),-113.874$

After multiple tests and experiments, the base plane equation obtained using Method (2) found to be very precise and suitable for this project. Using it as an input to the 3D camera sensor has shown a significant improvement in comparison with Method (1). Using the index (-113.874) as sea level index has provided more accurate results. Any minor change that falls within the range $(-110$ to -115$)$ on the sea level index could cause the sea level to shift up or down according to the change, however, any major change that does not falls within the safe range could cause total distortion and provide the user with wrong results.

Table $\mathrm{V}$ shows the difference in the corners positions obtained using Method (1) and Method (2). These four corners have changed in order to match the region where Ultra-short throw projector is projecting. Fig. 8 shows the projection region of the projector where it is not fully covering the entire interior of the box.

\section{TABLE V. CORNERS POSITIONS OF METHOD (1) AND} METHOD (2)

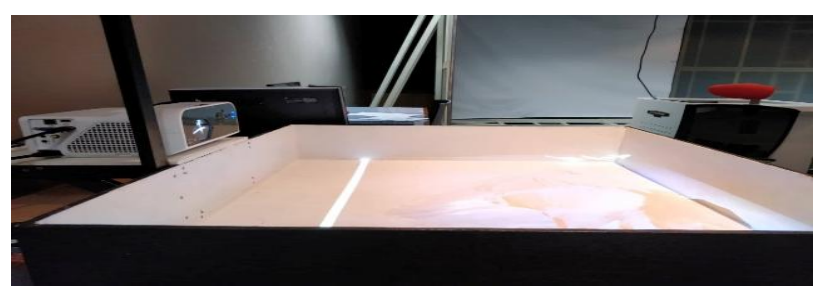

Fig. 8: The projection region is not fully covering the entire box

\section{RESULTS AND DISCUSSIONS}

\section{A. Calibration method results}

The position of ideal Four corner or Method (1) as in Table IV has provided wrong results as it can be seen in Fig. 9.

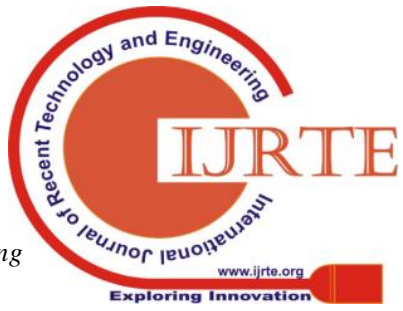


Sea level is covering the entire box and contour lines are of non-uniform shape, elevated map is not ranging in colour from blue to red but rather cover all in blue.

Results in Fig. 9 are to be improved as the calibration is not suitable and not functioning correctly given the entire box is covered with only blue colour simulating only water. This method has failed to reflect contour lines ranging in colours from cold blue to warm red according to the highest of the sand. Fig. 10 shows the improved results obtained from the proposed method (Method (2)).

Video of the proposed ARSAND can be viewed at the following link https://youtu.be/H7HMBmI37aE.

\section{B. Water Simulation}

Users can observe that water has been successfully simulated with the use of the AR sandbox software. After running the AR sandbox software and projecting the topographical map on the sandbox a user can simulate water in two ways.

First way by placing their hand at a certain height from the sand. Modification has been added to the software library to recognize the hand as an object needed to simulate water at a lower distance than the default one given the sandbox in this project is not filled up entirely. The second way is by using the graphical user interface (GUI) of the software itself as it provides a tool called (manage water locally) and it works by allowing the user to assign a keyboard button to rain where the mouse cursor is placed on the box.

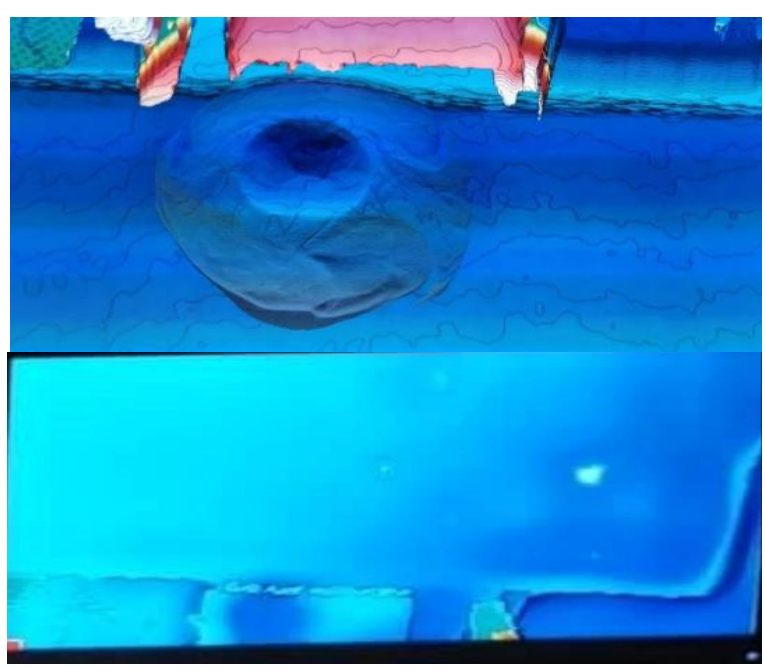

Fig.9: Results obtained from Method (1)

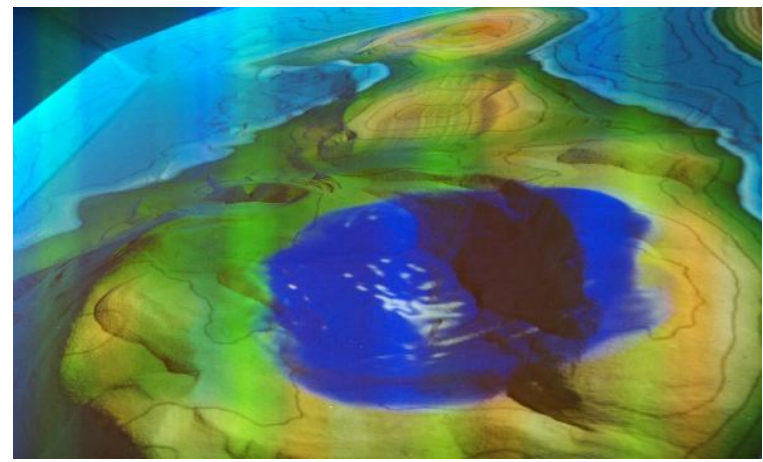

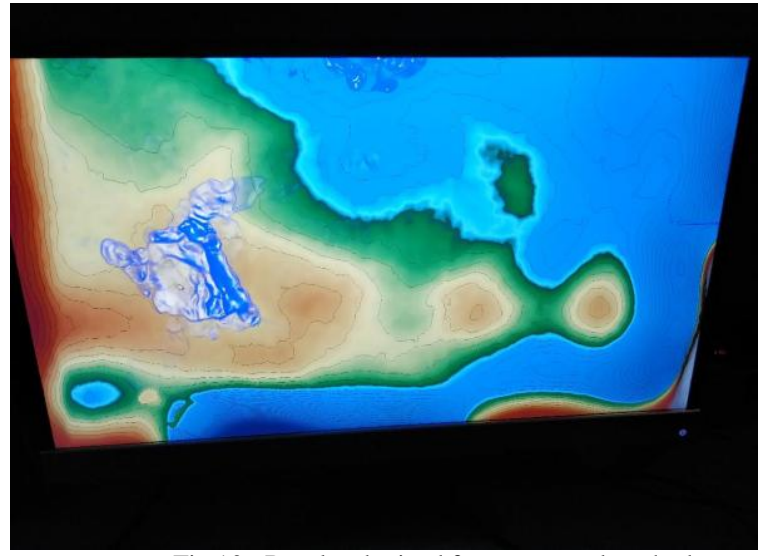

Fig.10: Results obtained from proposed method

\section{Larva Simulation}

Fig. 11 shows lava simulation sandbox view and monitor view respectively. Lava was simulated by extensively modifying the programming library used to simulate water, altering the colour and the shape of the water so it would mimic lava. The real time simulation can be done exactly the same ways as the water, either by placing the hand at a certain distance from the sandbox or placing the mouse cursor where lava is needed.

The project successfully able to simulate lava given its importance in geoscience and considering the study of volcano is of major research.

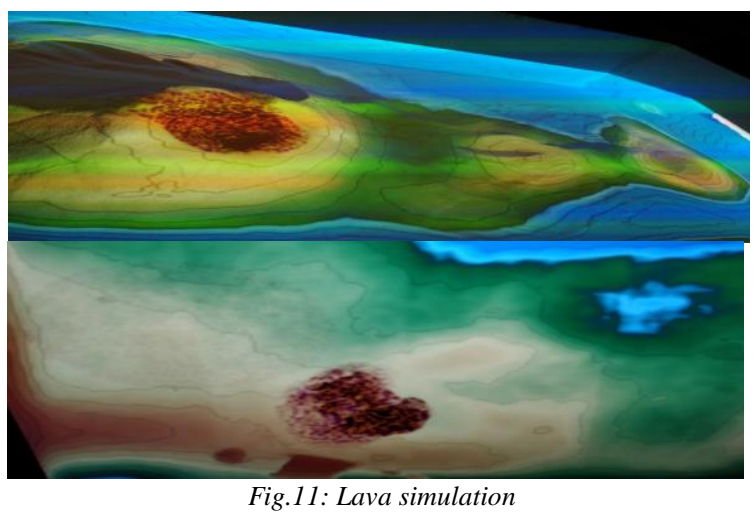

\section{CONCLUSION}

The proposed scaled version of ARSAND is able to perform basic functions of the original ARSAND such as simulating real-world terrain by having the elevated contour map coloured and drawn correctly according to the height of the sand. Water and additionally larva simulation are also successfully simulated using the proposed ARSAND, although ultra-short throw projector is used. Future work includes adding a short throw projector and mounting it on top of the sandbox that will make it project exactly within the four corners of the box and that will yield to even better results.

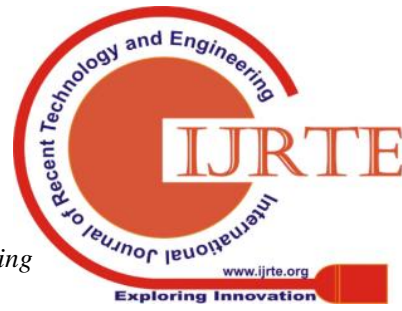




\section{ACKNOWLEDGMENT}

This research was fully funded by Faculty of Engineering and Faculty of Creative Multimedia, Multimedia University.

\section{REFERENCES}

[1] M. Nawaz, S. Kundu, and SattarFarha, “Augmented Reality Sandbox and Constructivist Approach for Geoscience Teaching and Learning," Int. J. Educ. Pedagog. Sci., vol. 11, no. 6, 2017.

[2] S. N. Kundu, N. Muhammad, and F. Sattar, "Using the augmented reality sandbox for advanced learning in geoscience education," Proc. 2017 IEEE Int. Conf. Teaching, Assess. Learn. Eng. TALE 2017, vol. 2018-Janua, no. December, pp. 13-17, 2018.

[3] B. A. Harmon, A. Petrasova, V. Petras, H. Mitasova, and R. Meentemeyer, "Tangible topographic modeling for landscape architects," Int. J. Archit. Comput., vol. 16, no. 1, pp. 4-21, 2018.

[4] S. Á. Sánchez, L. D. Martín, M. Á. Gimeno-González, T. Martín-Garcia, F. Almaraz-Menéndez, and C. Ruiz, "Augmented reality sandbox,” Proc. Fourth Int. Conf. Technol. Ecosyst. Enhancing Multicult. - TEEM '16, no. January 2018, pp. 599-602, 2016.

[5] B. L. Nielsen, H. Brandt, and H. Swensen, "Augmented Reality in science education - affordances for student learning," Nordina, vol. 12, no. 2, pp. 157-174, 2016.

[6] J. Doe, "Teaching Soils with an Augmented Reality Sandbox," CSA News, vol. 62, no. 11 , p. 8, 2017.

[7] P. Tabrizian et al., "Shaping watersheds exhibit: An interactive, augmented reality sandbox for advancing earth science education," ACADIA 2017 Discip. Disrupt. [Proceedings 37th Annu. Conf. Assoc. Comput. Aided Des. Archit., vol. 1, no. April, pp. 600-609, 2017.

[8] N. Pantuwong, N. Chutchomchuen, and P. Wacharawisoot, "Interactive topography simulation sandbox for geography learning course," Proc. 2016 8th Int. Conf. Inf. Technol. Electr. Eng. Empower. Technol. Better Futur. ICITEE 2016, 2017.

[9] T. Stabbert, T. Fröhlich, D. Alexandrovsky, and R. Malaka, "Extending Augmented Sandboxes with Virtual Reality Interaction," Mensch und Computer, 2017.

[10] P. Tabrizian, B. A. Harmon, A. Petrasova, H. Mitasova, and R. K. Meentemeyer, "Tangible Immersion for Ecological Design," ACADIA 2017 Discip. Disrupt. [Proceedings 37th Annu. Conf. Assoc. Comput AidedDes.Archit.,pp.600-609,2017.

\section{AUTHORS PROFILE}

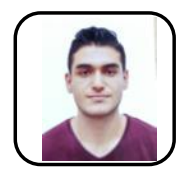

Fahad Muhyialdeen Aljabal is a recent graduate from Multimedia University, Cyberjaya, Malaysia in Bachelor of Engineering (Hons.) Electronics majoring in Telecommunications. He has an extensive experience in the field of augmented reality sandbox and networking. His work focuses specifically on the development of augmented reality and its implementation for educational purposes. He has worked as Networking Analyst for Schlumberger and gained variety of skills related to routing protocols, LAN and WAN management. His devotion lays mostly in reading and analysing scientific research papers related to engineering and health topics. His interests are in telecommunication, network and virtual reality.

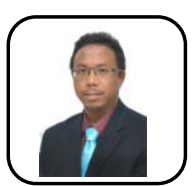

Hezerul Abdul Karim obtained his B.Eng. degree in Electronics with Communications from University of Wales Swansea, UK, in 1998 and M. Eng Science degree from Multimedia University, Malaysia in 2003. He obtained his $\mathrm{PhD}$ degree from Center for Communication Systems Research (CCSR), University of Surrey, UK in 2008. He is an Associate Professor at Multimedia University since November 2015. He is also Deputy Dean of Student Affair and Alumni at Faculty of Engineering, Multimedia University. He has been teaching multimedia and computing engineering subjects. His research interests include telemetry, 2D/3D image/video coding and transmission, error resilience and multiple description video coding, and deep learning in image and video. $\mathrm{He}$ is currently supervising and co-supervising several postgraduate students. He is Senior Member of IEEE and currently the Vice Chair of IEEE Signal Processing Society, Malaysia Section.

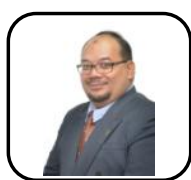

Mazlan Mahadzir is an Architect background. Currently a Head of Department for Product Design and Virtual Reality. He is a Specialist in Faculty of Creative Multimedia and Serving for more than 20 years for the university. He is also one of the project leader in Centre for Innovative Systemic Designs in Application and Content (CISDAC). He is also part of idea and development team for Nusajaya campus and HIVE project. His main interest includes virtual reality, virtual heritage, 3D animation, architectural visualisation and games

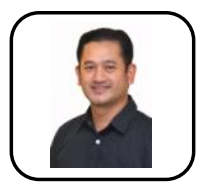

Mohd Hafizuddin Bin Mohd Yusof is a lecturer at Multimedia University (MMU) Cyberjaya since 1999 teaching Computing subjects. He is currently teaching in Media Arts Department at the Faculty of Creative Multimedia. He received his BSc degree in Computer Science majoring in Software Engineering from The University of Essex United Kingdom in 1999 and MSc in IT from MMU in 2005. He received his PhD from The University of Birmingham United Kingdom in July 2016. His interests include data science, machine learning, intelligent human computer interaction, computer vision and image processing.

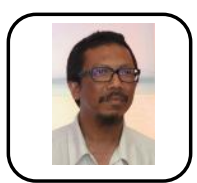

Che Zulkhairi Abdullah background is in design and development, which can be traced back to his academic background in functional design, analysis, programming and robotic. He received B.Sc. Housing Building and Planning (Architecture) from University Science of Malaysia, USM, Malaysia in 1993, M.Sc. Remote Sensing and Geographic Information System (GIS) from University Putra of Malaysia, UPM, Malaysia in 2005 and $\mathrm{PhD}$ Mechanical + Manufacturing Engineering from The University of Birmingham, UK. In Dec 2013. He was an academic at Multimedia University Malaysia between 1999-2008 and 2014-2015 in the subject area of Film \& animation, Game, Virtual Reality and Interface Design. He was working as Research Fellow for two different funded projects (EPSRC and IOSH) at The University of Nottingham from 2016-2018. His current research is on distributed collaborative environment for analysing near real-time 3D satellite data for disaster interventions. 